\title{
Effect of cycloheximide on intestinal secretion induced by hypertonic glucose ${ }^{1}$
}

\author{
C.H.HALSTED, D. I. GRAYER, E.H.LUEBBERS, J.H. YARDLEY, AND T.R. HENDRIX \\ From the Departments of Medicine and Pathology, The Johns Hopkins University School of Medicine, \\ Baltimore, Maryland 21205, USA
}

SUMMARY Since intestinal fluid production in experimental cholera can be limited by cycloheximide, an inhibitor of protein synthesis, the same agent was used to determine whether there are similar mechanisms for fluid production in response to an osmotic gradient. Intestinal fluid production was measured by perfusion of paired rabbit jejunal loops $(10 \mathrm{~cm})$ in vivo, in controls, and in animals receiving $20 \mathrm{mig} / \mathrm{kg}$ intravenous cycloheximide one hour before perfusion. In each animal one loop was perfused with isotonic Ringer's lactate and the other with a hypertonic glucose-Ringer's lactate solution, $563 \mathrm{mOsm} /$ litre. In control animals mean fluid production in the hypertonic loop was seven times that in the isotonic loop. Cycloheximide decreased the fluid response to the hypertonic stimulus by one half $(P<0.001)$. In a separate measurement of bidirectional sodium fluxes, using sodium ${ }^{22}$, it was shown that the decreased net sodium movement into the lumen observed after cycloheximide was the result of decreased flux from blood to lumen. The major histological alteration after cycloheximide was on the crypt epithelial cells with sparing of villus crests. Glucose absorption was unaffected. These data parallel the observed effect of cycloheximide on cholera exotoxin induced secretion, suggesting that a process requiring continued protein synthesis is also necessary for the intestinal fluid response to an osmotic gradient.

Intravenous cycloheximide prevents the cholera exotoxin induced movement of fluid into loops of rabbit jejunum. Glucose absorption is unaffected by the combination of intravenous cycloheximide and intraluminal cholera exotoxin (Serebro, Iber, Yardley, and Hendrix, 1969). Studies of bidirectional sodium fluxes indicate that the major effect of cycloheximide is in diminishing the cholera exotoxin stimulated movement of sodium into the lumen (Grayer, Serebro, Iber, and Hendrix, 1970). The present studies were undertaken to determine whether cycloheximide inhibits fluid secretion induced by an osmotic gradient as well as fluid secretion induced by cholera exotoxin. Pretreatment with cycloheximide was found to diminish by one half the secretory response to an osmotic gradient.

\section{Methods}

PERFUSION STUDIES

Twenty New Zealand male rabbits weighing 3 to 5 pounds were anaesthetized with intravenous pentobarbital, and hydration was maintained during

${ }^{2}$ This work was presented in part at the meeting of the American Gastroenterological Association in May 1969.

Reseived for publication 18 November 1970. the course of the experiment with intravenous Ringer's lactate at a rate of $25 \mathrm{ml} / \mathrm{hr}$. Paired, in-vivo jejunal loops, $10 \mathrm{~cm}$ in length, were constructed in each animal so that the circulation remained intact. The proximal loop (A) originated at the ligament of Treitz and the distal loop (B) was immediately adjacent. Ten rabbits were controls, and 10 received cycloheximide $(20 \mathrm{mg} / \mathrm{kg}$ intravenously) one hour before the start of perfusion. Jejunal biopsies were taken from each loop before perfusion and the administration of cycloheximide and again at the conclusion of the experiment.

The perfusing solution (Ringer's lactate) contained $\mathrm{Na}^{+} 130, \mathrm{~K}^{+} 4, \mathrm{Cl}^{-} 109, \mathrm{Ca}^{++3} \mathrm{~m}$-equiv/l, and lactate $28 \mathrm{mM} / 1$, to which was added $0.3 \mathrm{mM} / \mathrm{l}$ phenol red, as a poorly absorbed marker. Glucose, $5.6 \mathrm{mM} / \mathrm{l}$, was added to the solution for isotonic perfusion of the A loop. The solution for perfusion of the B loop was made hypertonic ( $563 \mathrm{mOsm} / \mathrm{litre})$ by the addition of $277.5 \mathrm{mM} / \mathrm{l}$ of glucose.

Using a Technicon proportioning pump, each solution was perfused through its respective loop at a rate of $2 \mathrm{ml} / \mathrm{min}$ from a $30 \mathrm{ml}$ reservoir over a period of three hours. The perfusate returned to the reservoir for recycling through the loop. Samples, 262 
$2 \mathrm{ml}$, were taken from each reservoir after seven minutes' equilibration and at intervals of 30 minutes during the study. At the completion of the three-hour perfusion, the loops were removed, divided along the antimesenteric border, and the lengths measured.

The concentrations of glucose and phenol red were measured in each sample by standard methods (Hoffman, 1937; Schedl and Clifton, 1961). Osmolality was measured by freezing point depression, sodium and potassium by flame photometry, and chloride by a Buchler-Cotlove chloridometer.

Net fluid movement was determined from the change in concentration of phenol red. Net movement of glucose, sodium, and chloride over the three-hour period was determined by measuring the difference between the amount of each constituent present in the reservoir at the start and the amount present at the end of perfusion, corrected for the amount removed by sampling.

\section{FLUX STUDIES}

Bidirectional fluxes of sodium were determined in 10 rabbits, five of whom received cycloheximide, $20 \mathrm{mg} / \mathrm{kg}$ intravenously, four hours before study. In each rabbit, a jejunal loop of $10 \mathrm{~cm}$ was constructed and closed at the distal end. A multiperforated polyethylene catheter was inserted the length of the loop and the proximal end of the loop was closed around it. Except for the addition of trace amounts of ${ }^{22} \mathrm{Na}(0.02 \mu \mathrm{c} / \mathrm{ml})$, the instillation solution was identical to that used in the hypertonic B loop perfusion. Seven $\mathrm{ml}$ were instilled and $1.5 \mathrm{ml}$ samples were removed at 30 seconds and at 10 and 60 minutes. After sacrifice, the loop length was measured as described above. Using the model of Berger and Steele (1958), the transfer rates of sodium out of the loop $\left(\mathrm{J}_{\alpha}{ }^{\mathrm{Na}}\right)$, into the loop $\left(\mathrm{J}_{\beta}{ }^{\mathrm{Na}}\right)$ and net movement of sodium (the difference) were calculated for the 10 to 60 minute period. Glucose absorption was also determined as described for the perfusion experiment.

Values in both sets of experiments are expressed as mean \pm SEM. Student's $t$ test was used to determine significance.

\section{Results}

\section{FLUID MOVEMENT}

The validity of using volumes calculated from concentrations of phenol red is based on adequate and equal recovery of phenol red in each group, viz, control isotonic $93.9 \pm 0.96 \%$, control hypertonic $95 \cdot 2 \pm 1 \cdot 49 \%$, cycloheximide isotonic $95 \cdot 2 \pm 1 \cdot 35 \%$, and cycloheximide hypertonic $96 \cdot 6 \pm 1 \cdot 12 \%$. Figure 1 illustrates the net fluid movement in the perfused loops (A and $\mathrm{B}$ ) of the control and treated animals. Perfusion of the jejunal loops with the isotonic solution (A) over a period of three hours was associated with a net movement into the loop of $106 \pm 63.0$ $\mu \mathrm{l} / \mathrm{cm}$ in the control animals, which was unaffected by previous treatment with cycloheximide $(33 \pm 64 \cdot 0$ $\mu \mathrm{l} / \mathrm{cm}, \quad \mathrm{P}>0 \cdot 15)$. Perfusion with the hypertonic solution (B) produced a net fluid movement into the loop of $725 \pm 46.0 \mu \mathrm{l} / \mathrm{cm}$ over three hours. In contrast, the net fluid movement into the B loop (hypertonic) of the animals pretreated with cycloheximide was

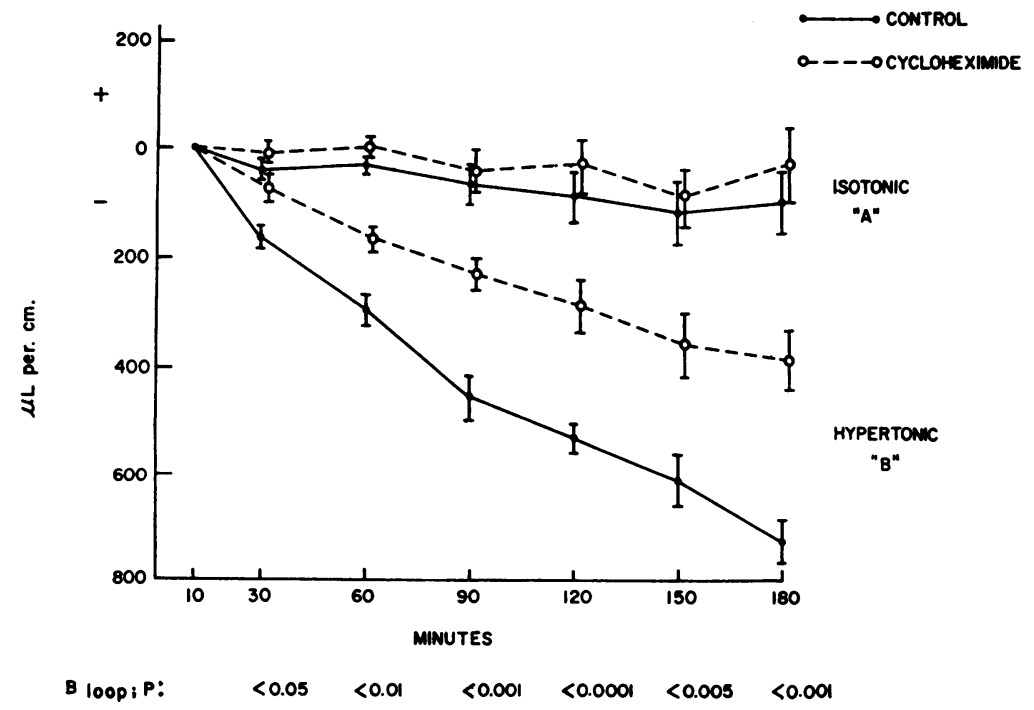

Fig. 1 Net fluid movement over three hours of continuous perfusion of jejunal loops in vivo with isotonic and hypertonic glucose solutions. Intravenous cycloheximide $(20$ $\mathrm{mg} / \mathrm{kg}$ ), administered one hour before the start of perfusion, had no significant effect on fluid movement into the isotonic loops. A significant decrease in fluid movement was effected by cycloheximide after 30 minutes of hypertonic perfusion $(\mathrm{P}<0.05)$ which became highly significant at three hours $(\mathrm{P}<0.001)$. 
only $382 \pm 60.0 \mu \mathrm{l} / \mathrm{cm}$. The decrease in net fluid movement became significantly different from the untreated animals after 30 minutes of perfusion $(P<0.05)$, and persisted over the three-hour period (P<0.001).

\section{OSMOLALITY CHANGE}

The osmolality of the hypertonic perfusion at the start was $562 \cdot 8 \pm 90 \mathrm{mOsm} / \mathrm{l}$ (Fig. 2). In the control animals after three hours of perfusion the osmolality fell by $24.9 \%$ to a concentration of $422 \cdot 7 \pm 7 \cdot 88$ $\mathrm{mOsm} / \mathrm{l}$. In contrast, the osmolality of the perfusate in those animals treated with cycloheximide fell only to $472.8 \pm 13.49 \mathrm{mOsm} / \mathrm{l}$, a dilution of $15.9 \%$ (P $<0.001)$.

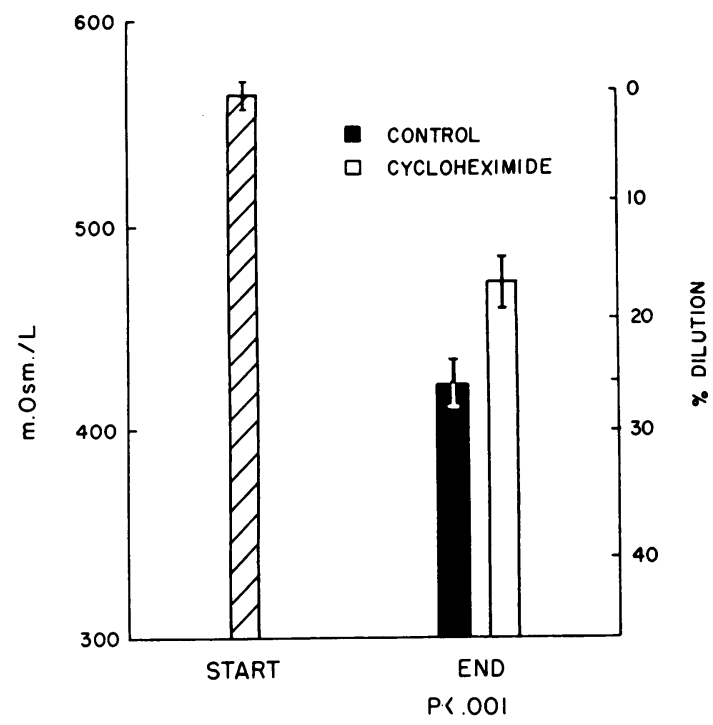

Fig. 2 Change in osmolality of the hypertonic perfusate; comparison of decrease from initial osmolality $(n=20)$ by three hours of continuous perfusion in control $(n=10)$ and animals treated with cycloheximide $(n=10)$. Because of the decreased net fluid movement in the cycloheximide treated animals, the fall in osmolality, expressed as an absolute value and as a mean percentage of the original, was significantly less in the treated group than in the control group.

\section{GLUCOSE ABSORPTION}

The absorption of glucose from the isotonic solution was the same in the control and treated animals (control, $5 \cdot 6 \pm 1 \cdot 10 \mu \mathrm{M} / \mathrm{cm} / 3 \mathrm{hr} v$ treated, $5 \cdot 3 \pm$ $0.87 \mu \mathrm{M} / \mathrm{cm} / 3 \mathrm{hr} ; \mathrm{P}>0.80$ ) (Fig. 3). The mean absorption was greater from the B loops because of the larger amount of glucose in the perfusing

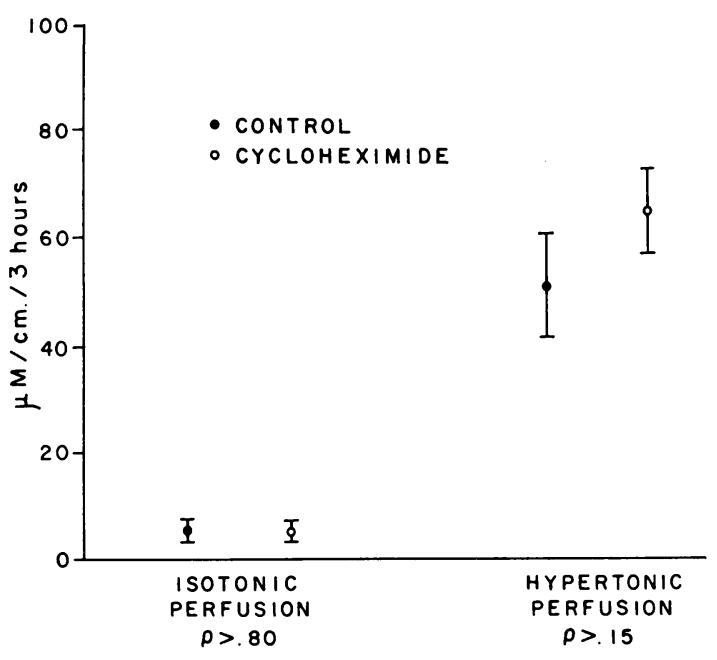

Fig. 3 Glucose absorption from the isotonic and hypertonic perfused loops. Mean \pm SEM is shown for each group. Absorption was greater from the hypertonic than from the isotonic loops because of the greater initial concentration of glucose in the former. Cycloheximide pretreatment did not alter absorption in either group.

solution. Glucose absorption was similarly unaffected by cycloheximide in the loops perfused by the hypertonic solution (control, $51 \cdot 5 \pm 9 \cdot 20 \mu \mathrm{M}$ / $\mathrm{cm} / 3 \mathrm{hr} \quad v$ treated $64.4 \pm 7.80 \mu \mathrm{M} / \mathrm{cm} / 3 \mathrm{hr}$; $P>0 \cdot 15)$.

\section{ELECTROLYTE MOVEMENT}

The net movement of sodium and chloride in the B loop (hypertonic) over the three-hour perfusion,

\begin{tabular}{|c|c|c|c|c|}
\hline & $\begin{array}{l}\text { Sodium }(\mu-e q u i v / c m / 3 ~ h r \\
\pm S E M)\end{array}$ & $\begin{array}{l}\text { Chloride }(\mu-e q u i v / \mathrm{cm} / 3 \mathrm{hr} \\
\pm S E M)\end{array}$ & $\begin{array}{l}\text { Volume }(\delta \mathrm{l} / \mathrm{cm} / 3 \mathrm{hr} \\
\pm S E M)\end{array}$ & $\begin{array}{l}\text { Apparent Sodium Con- } \\
\text { centration (m-equiv/l } \\
\pm S E M)\end{array}$ \\
\hline
\end{tabular}

Table I Net movement of sodium and chloride

${ }^{1}$ Negative values indicate movement into the loop and positive values movement out of the loop. 

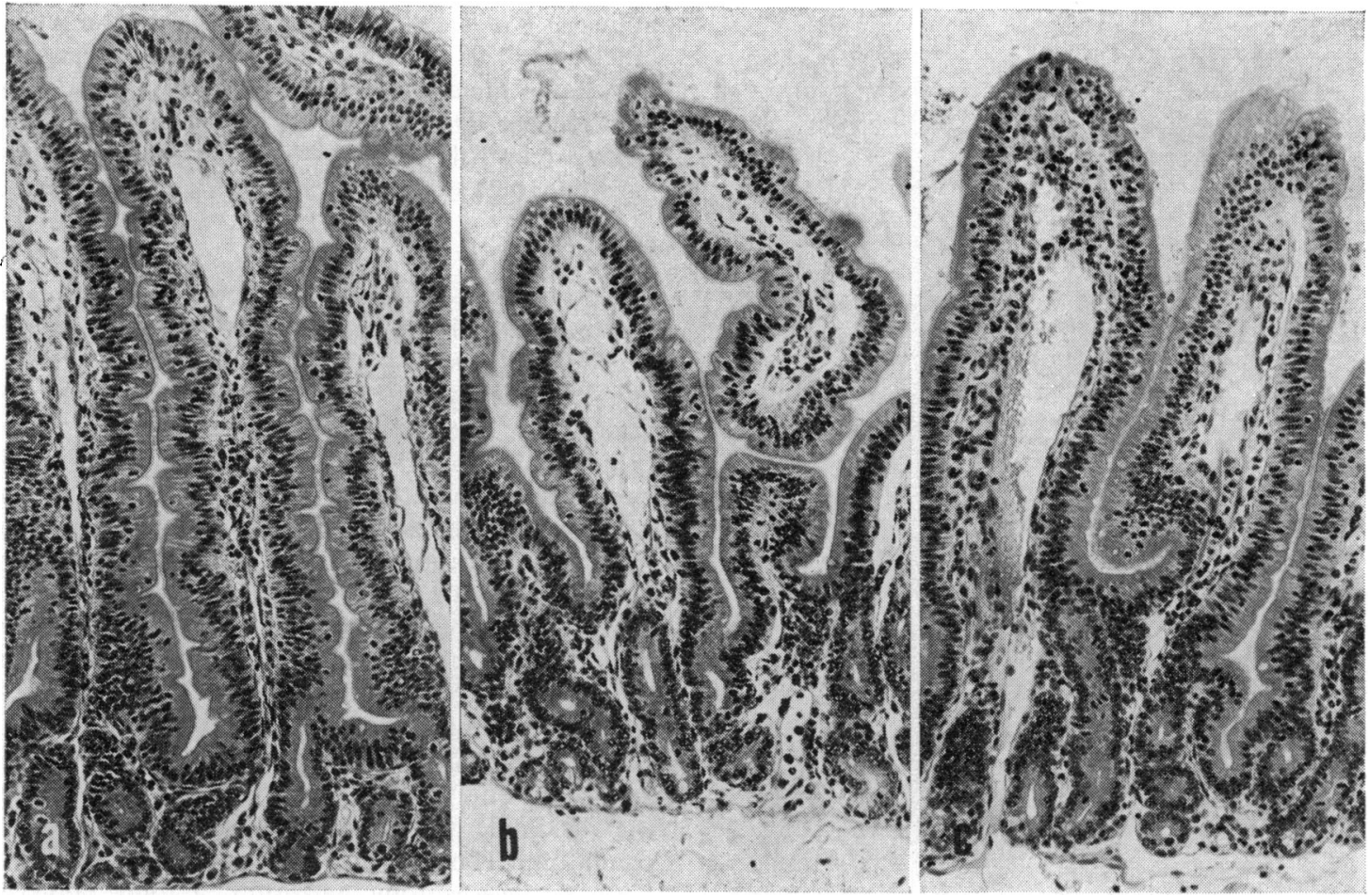

Fig. 4 Intestinal mucosa from a control animal $(\times 165)$. a Mucosa before perfusion; $b$ mucosa from $A$ loop after three hours' perfusion with isotonic solution: c mucosa from B loop after three hours' perfusion with hypertonic solution.

is shown in Table I. In the cycloheximide-treated animals there was net absorption of chloride. However, as shown by the difference of means between the control and treated groups, the effect of cycloheximide on sodium movement was similar in amount and direction to that of chloride. The apparent concentration of sodium in the net transfer fluid, calculated in each animal by dividing net sodium by net fluid movement, was essentially the same in the control and treated groups $(69 \cdot 1 \pm$ 9.86 m-equiv/l $v 66 \cdot 1 \pm 12.44$ m-equiv/l; $\mathrm{P}>0.70$ ).

\section{HISTOLOGICAL OBSERVATIONS}

No significant histological alterations were seen in the intestinal mucosa of control animals subjected to three hours of continuous perfusion with either the isotonic or hypertonic glucose electrolyte solution (Fig. 4). In each animal cycloheximide had a histologically comparable effect on the $\mathbf{A}$ and B loop. More variability of mucosal response to the $20 \mathrm{mg} / \mathrm{kg}$ dose of cycloheximide was encountered than seen in previous experiments (Serebro et al, 1969), but in the majority of the animals the changes were minimal. In the rabbits demonstrating minimal alterations there was disappearance of mitotic figures in the crypts of Lieberkühn and pyknosis and karyorrhexis in lymphoid cells of the lamina propria (Figs. 5a and 5b). The crypt and villous epithelial cells were normal except for scattered basophilic bodies like those in the lamina propria. The latter probably were derived chiefly from interepithelial lymphocytes. In three animals demonstrating the most severe mucosal derangement following cycloheximide nearly total destruction of some crypts was observed (Fig. 5d). On the other hand, the villous epithelium in all animals showed, at the most, focal reduction in epithelial cell height and scattered basophilic bodies (Figs. 5a and 5c). There was no observable loss of villous epithelial integrity.

The inhibition of secretion was as great in those animals whose biopsies showed minimal histological evidence of cycloheximide toxicity as in those showing the more severe changes.

\section{UNIDIRECTIONAL SODIUM FLUXES (TABLE II)}

In the closed loop preparation, pretreatment with cycloheximide also decreased net fluid production by over one half. Net and unidirectional sodium fluxes were significantly decreased in the treated 


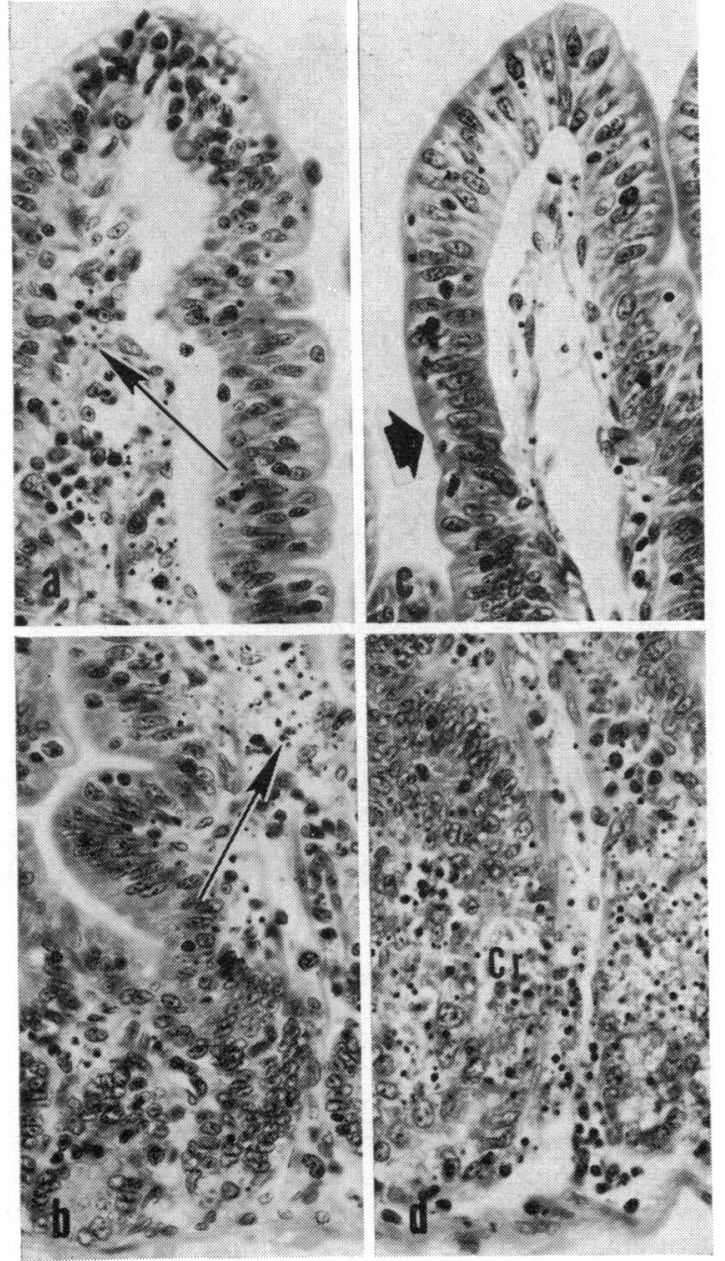

Fig. 5 Effect of cycloheximide on mucosa $(\times 385)$. a and $\mathrm{b}$ demonstrate the villus and crypt regions respectively of a rabbit loop which showed minimal changes; $\mathrm{c}$ and $\mathrm{d}$ are from comparable areas of a loop showing maximal injury taken from another animal. In both $\mathrm{a}$ and $\mathrm{b}$ the lamina propria is mainly affected, lymphoid cells demonstrating pyknosis and karyorrhexis (thin arrows). The villus shown in $\mathrm{c}$ is similar to that seen in a except for focal epithelial thinning (thick arrow). animals. The decrease of mean flux into the lumen $\left(\mathrm{J}_{\beta}^{\mathrm{Na}}\right)$ was $1.08 \mu$-equiv $/ \mathrm{cm} / \mathrm{min}$, and of mean flux out of the lumen $\left(\mathrm{J}_{\alpha}{ }^{\mathrm{Na}}\right)$ was $0.48 \mu$-equiv $/ \mathrm{cm} / \mathrm{min}$. Net glucose absorption was similar in the two groups (control, $0.27 \pm 0.04 \mu \mathrm{M} / \mathrm{cm} / \mathrm{min} v$ cycloheximide, $0.24 \pm 0.04 \mu \mathrm{M} / \mathrm{cm} / \mathrm{min}$ ).

\section{Discussion}

Cycloheximide, an antibiotic produced by Streptomyces griseus, is an inhibitor of protein synthesis which interferes with ribosome formation (Trakatellis and Montjar, 1968), and the transfer of amino acids from SRNA to nascent polypeptide chains (Ennis and Lubin, 1964). As a metabolic poison, it has been employed to block the experimental production of intestinal fluid by cholera exotoxin, with the implication that there exist active secretory processes in the small intestine (Serebro et al, 1969). The present studies were performed to determine whether osmotically induced secretion, heretofore attributed to purely physical forces, could be similarly affected by cycloheximide.

Net fluid movement was compared in isotonic and hypertonic glucose solutions, and the effect of cycloheximide on fluid movement measured in each condition. The small amount of net secretion observed with isotonic perfusion (A loop) approximated that described in a similar preparation in the guinea pig (Powell, Malawer, and Plotkin, 1968). Perfusion with a hypertonic glucose solution $(563 \mathrm{mOsm} / \mathrm{l})$ produced a seven-fold increase in net secretion over three hours. Whereas isotonic fluid movement was unaffected by cycloheximide, the stimulated net secretion was reduced by one half.

The inhibitory effect of cycloheximide on net secretion could be due to a decreased movement into the lumen, an increased movement out of the lumen, or a combination of these two effects. Using a technique of instillation into a closed loop, cycloheximide pretreatment was observed to decrease net fluid production to the same degree as observed in the perfusion experiments. Following cycloheximide the net flux of sodium was decreased, in association with diminished unidirectional fluxes.

\begin{tabular}{|c|c|c|c|c|}
\hline & \multirow{2}{*}{$\begin{array}{l}\text { Net Fluid Flux } 1(\mu / / c m / m i n \\
\pm S E M)\end{array}$} & \multicolumn{3}{|c|}{ Unidirectional Fluxes ( $\mu-e q u i v / \mathrm{cm} / \mathrm{min}$ ) } \\
\hline & & $\underset{n e t}{J^{N a}}$ & $\underset{a}{J_{a}}$ & $\underset{\beta}{\mathrm{Na}}$ \\
\hline $\begin{array}{l}\text { Control }(n=5) \\
\text { Cycloheximide }(n=5) \\
\text { P }\end{array}$ & $\begin{array}{l}9 \cdot 28 \pm 2 \cdot 358 \\
3.78 \pm 0.354 \\
<0.05\end{array}$ & $\begin{array}{l}0.903 \pm 0.300 \\
0.297 \pm 0.067 \\
<0.05\end{array}$ & $\begin{array}{l}1.64 \pm 0.190 \\
1 \cdot 16 \pm 0.090 \\
<0.05\end{array}$ & $\begin{array}{l}2.54 \pm 0.480 \\
1.46 \pm 0.110 \\
<0.05\end{array}$ \\
\hline
\end{tabular}

Table II Fluid and sodium fuxes in loops exposed to hypertonic glucose

IInto the lumen. 
Although unidirectional sodium transfer out of the lumen $\left(J_{\alpha}{ }^{\mathrm{Na}}\right)$ was significantly decreased, this change alone would lead to an increased accumulation of sodium in the loop, contrary to the observed effect. Therefore, the net decrease of sodium movement into the lumen after cycloheximide must be attributed to the inhibition of unidirectional sodium transfer into the lumen $\left(\mathrm{J}_{\beta}{ }^{\mathrm{Na}}\right)$.

Small-intestinal fluid response to an osmotic gradient is generally believed to occur by filtration through membrane pores. The initial observation of different responsiveness of the jejunum and ileum to hypertonicity (Hindle and Code, 1962) was followed by the determination of the fluid response at these sites to different sized molecular species (Fordtran, Rector, Ewton, Soter, and Kinney, 1965). From these data have been calculated different sized membrane pores for jejunum and ileum. Conceivably in the present series cycloheximide inhibited the filtration process by effecting a decrease in pore size. An alternate explanation for inhibition of fluid movement by cycloheximide is that the agent blocked a specific mechanism for solute transfer into the lumen. The similarity of apparent sodium concentration of the net transport fluid in the control and treated groups (Table I) is consistent with either possibility.

The present data suggest a heterogeneity of function of the small-intestinal mucosa. Absorption of glucose, known to be a function of the columnar cells of the villus crest (Kinter and Wilson, 1965), was unaffected by cycloheximide at the same time as fluid production was inhibited by one half. Morphologically, the villus crest was spared at the same time as a spectrum of damage occurred at the crypt level. Time studies of the effect of cycloheximide on rat small intestine indicate that suppression of crypt mitoses coincides with a block of protein synthesis in the $\mathbf{G} 2$ phase of cell replication (Verbin and Farber, 1967). In the present studies functional changes occurred after $\mathbf{3 0}$ minutes of perfusion, or one and one half hours after administration of cyclohexamide. Parallel studies show that at one to two hours after cycloheximide the only morphological change is arrest of mitoses in the crypts (Harper, Yardley, and Hendrix, 1970).

A process dependent upon continued protein synthesis in the crypts may be necessary for the secretory response to an osmotic gradient. However, in contrast to nearly complete suppression of cholera-induced secretion by cycloheximide (Serebro et al, 1969), the response to an osmotic gradient was limited by only one half. Therefore, it is probable that an osmotic force affects different or additional secretory mechanisms than those operative in cholera-stimulated secretion.
Trans-intestinal fluid transport may require continuing protein synthesis to provide (1) one or more membrane proteins important in regulating 'effective pore size'; (2) intracellular acceptor and transport systems; or (3) maintenance of normal intracellular energy levels. The third possibility is unlikely, since cycloheximide at a dose limiting osmotic secretion did not alter glucose absorption. Our data do not allow a precise differentiation between the first two possibilities. Membrane permeability could be affected at a submicroscopic level. However, the association of crypt damage and suppression of fluid production by cycloheximide without an alteration of glucose absorption suggests that the crypts may be a site for the physiological transfer of solute and water into the lumen.

Supported in part by research grants AI08602 and AI08187 from the US Public Health Service and US Public Health Service National Institutes of Health graduate training grant no. AM05095. Dr Yardley is the recipient of a research career development award from the US Public Health Service.

\section{References}

Berger, E. Y., and Steele, J. M. (1958). The calculation of transfer rates in two compartment systems not in dynamic equilibrium. J. gen. Physiol., 41, 1135-1152.

Ennis, H. L., and Lubin, M. (1964). Cycloheximide: aspects of inhibition of protein synthesis in mammalian cells. Science, 146, 1474-1476.

Fordtran, J. S., Rector, F. C., Jr., Ewton, M. F., Soter, N., and Kinney, J. (1965). Permeability characteristics of the human small intestine. J. clin. Invest., 44, 1935-1944.

Grayer, D. T., Serebro, H. A., Iber, F. L., and Hendrix, T. R. (1970). Effect of cycloheximide on unidirectional sodium fluxes in the jejunum after cholera exotoxin exposure. Gastroenterology, 58, 815-819.

Harper, D. T., Yardley, J. H., and Hendrix, T. R. (1970). Reversal of cholera exotoxin-induced jejunal secretion by cycloheximide. Johns Hopk. med. J., 126, 258-266.

Hindle, W., and Code, C. F. (1962). Some differences between duodenal and ileal sorption. Amer. J. Physiol., 203, 215-220.

Hoffman, W. S. (1937). A rapid photoelectric method for the determination of glucose in blood and urine. J. biol. Chem., 120, 51-55.

Kinter, W. B., and Wilson, T. H. (1965). Autoradiographic study of sugar and amino acid absorption by everted sacs of hamster intestine. J. Cell Biol., 25 (2, ii) 19-39.

Powell, D. W., Malawer, S. J., and Plotkin, G. R. (1968). Secretion of electrolytes and water by the guinea pig small intestine in vivo. Amer. J. Physiol., 215, 1226-1233.

Schedl, H. P., and Clifton, J. A. (1961). Small intestinal absorption of steroids. Gastroenterology, 41, 491-499.

Serebro, H. A., Iber, F. L., Yardley, J. H., and Hendrix, T. R. (1969). Inhibition of cholera toxin action in the rabbit by cycloheximide. Gastroenterology, 56, 506-511.

Trakatellis, A. C., and Montjar, M. J. (1968). Effect of cycloheximide on ribosome formation in the mouse liver. Life Sciences, 7 , 413-419.

Verbin, R. S., and Farber, E. (1967). Effect of cycloheximide on the cell cycle of the crypts of the small intestine of the rat. J. Cell Biol., 35, 649-658. 